\title{
A ESTRUTURA FUNDIÁRIA NO BRASIL E A LUTA PELA REFORMA AGRÁRIA: O ACAMPAMENTO E A ESCOLA ITINERANTE VALMIR MOTTA DE OLIVEIRA EM JACAREZINHO-PR
}

\author{
Recebido em 16/01/2020, aprovado em 12/03/2020 \\ 10.30612/mvt.v6i11.10902 \\ Marcio Luiz Carreri ${ }^{13}$ \\ Gabriely Cristine de Souza ${ }^{14}$
}

\begin{abstract}
RESUMO: O texto apresenta um debate sobre a histórica estrutura fundiária brasileira e sua modernização conservadora, discute a relação entre a propriedade e posse da terra no Brasil e a necessidade e a luta pela reforma agrária, com a atuação do Movimento dos Trabalhadores Rurais Sem Terra (MST) e da Comissão Pastoral da Terra (CPT). Trabalha também um breve estudo sobre a Educação Popular e estuda um caso especial, o acampamento Valmir Motta de Oliveira em Jacarezinho, estado do Paraná, local que associa a luta pela terra e a educação no contexto da sociedade brasileira. Parte da análise específica do acampamento e da escola itinerante e, para o desenvolvimento da pesquisa utilizamos, basicamente, de trabalho de campo e entrevistas no próprio acampamento e na escola, além da historiografia sobre o tema. A pesquisa é importante para a comunidade conhecer a história e a luta de um movimento social a partir de uma experiência local, obtendo, dessa forma, um melhor entendimento do significado desse Movimento e da luta pela terra e pela educação, no país, no estado e no local onde vive.
\end{abstract}

Palavras-chave: Modernização Conservadora. Reforma Agrária. MST. Educação Popular.

\section{THE LANDY STRUCTURE IN BRAZIL AND THE FAGHT FOR AGRICULTURAL REFORM: THE VALMIR MOTTA DE OLIVEIRA CAMP IN JACAREZINHO-PR}

ABSTRACT: The text presents a debate about the historical Brazilian land structure and its conservative modernization, discusses the relationship between land ownership and tenure in Brazil, and

13 Doutor em História pela PUC-SP e Pós-Doutorando em História Social pela USP. Professor do Colegiado de História da Universidade Estadual do Norte do Paraná (UENP), Campus Jacarezinho. E-mail carreri@uenp.edu.br.

14 Graduanda em Licenciatura em História pela UENP. Pesquisadora do Grupo de Pesquisa História, Cultura e Marxismo. Bolsista do programa PIBIC/Fundação Araucária. E-mail: gabysouza090198@gmail.com. 
the necessity and struggle for agrarian reform, with the action of the Movimento dos Trabalhadores Rurais Sem Terra (MST) and the Comissão Pastoral da Terra (CPT). He is also working on a brief study on Popular Education and studying a special case, the Valmir Motta de Oliveira camp in Jacarezinho, state of Paraná, a place that combines the struggle for land and education in the context of Brazilian society. Part of the specific analysis of the camp and the itinerant school and, for the development of the research, we basically use fieldwork and interviews in the camp and at the school, in addition to the historiography on the subject. The research is important for the community to know the history and struggle of a social movement from a local experience, thus obtaining a better understanding of the meaning of that Movement and the struggle for land and education, in the country, in the state and where you live.

Keywords: Conservative Modernization. Land reform. MST. Popular Education.

\section{LA ESTRUCTURA FUNDAMENTAL DE LA TIERRA EN BRASIL Y LA LUCHA POR LA REFORMA AGRÍCOLA: EL CAMPAMENTO VALMIR MOTTA DE OLIVEIRA EN JACAREZINHO-PR}

RESUMEN: El texto presenta un debate sobre la estructura histórica de la tierra brasileña y su modernización conservadora, discute la relación entre la propiedad y la tenencia de la tierra en Brasil, y la necesidad y la lucha por la reforma agraria, con la acción del Movimento dos Trabalhadores Rurais Sem Terra (MST) y la Comissáo Pastoral da Terra (CPT). También trabaja en un breve estudio sobre Educación Popular y estudiando un caso especial, el campamento Valmir Motta de Oliveira en Jacarezinho, estado de Paraná, un lugar que combina la lucha por la tierra y la educación en el contexto de la sociedad brasileńa. Parte del análisis específico del campamento y la escuela itinerante y, para el desarrollo de la investigación, básicamente utilizamos trabajo de campo y entrevistas en el campamento y en la escuela, además de la historiografía sobre el tema. La investigación es importante para que la comunidad conozca la historia y la lucha de un movimiento social a partir de una experiencia local, obteniendo así una mejor comprensión del significado de ese Movimiento y la lucha por la tierra y la educación, en el país, en el estado y donde vives

Palabras clave: Modernización conservadora. Reforma agraria. MST. Educación Popular.

\section{INTRODUÇÃO}

O texto apresenta um debate sobre a histórica estrutura fundiária brasileira e sua modernização conservadora, e discute a relaçáo entre a propriedade e posse da terra no Brasil, bem como a necessidade e a luta pela reforma agrária, com a atuação do Movimento dos Trabalhadores Rurais Sem Terra (MST) e da Comissão Pastoral da Terra (CPT). Trabalha também um breve estudo sobre a educação popular e estuda um caso especial, o acampamento Valmir Motta de Oliveira em Jacarezinho, no estado do Paraná, local que associa a luta pela terra e a educação no contexto da sociedade brasileira. 
A realização da pesquisa que resultou neste presente texto, ocorreu calcada em análises de pesquisas de fundamentação a respeito da formação e consequências do capitalismo e da formação e objetivos do MST na luta pela terra como resistência a esse sistema no âmbito da luta de classes. O desenvolvimento da pesquisa se deu, também, por meio de trabalho de campo e entrevistas, visando que um dos objetivos é compreender o aspecto histórico, significado e relevância do acampamento Valmir Motta de Oliveira e da Escola Itinerante Valmir Motta de Oliveira localizados em Jacarezinho-PR, como parte de um todo que é o Movimento. Henry Rousso (2000, p.94) resume a perspectiva aqui adotada da importância das entrevistas e do trabalho de campo, no âmbito da História Oral:

A memória, para prolongar essa definição lapidar, é uma reconstrução psíquica e intelectual que acarreta de fato uma representaçáo seletiva do passado, um passado que nunca é aquele do indivíduo somente, mas de um indivíduo inserido num contexto familiar, social, nacional.

O trabalho de campo e as entrevistas com educadores sobre o acampamento e a Escola são essenciais para compreender melhor as análises das teorias na prática, assim, a luta pela terra (como reflexo da luta de classes) e a outra proposta de educação da Escola Itinerante, a Educação Popular, terâo sua relevância e seu significado para a sociedade de maneira ainda mais clara e com mais informaçôes que ajudará na apreensão do porquê da existência do acampamento e da Escola, além de entender a importância da escola, também, para o próprio acampamento.

Portanto, os objetivos da pesquisa foram alcançados por meio de pesquisas bibliográficas para a compreensão da causa da formação do Movimento, partindo de entender o todo através do específico com o estudo do acampamento Valmir Motta de Oliveira e da Escola Itinerante Valmir Mota de Oliveira para compreender a importância e seus significados dentro do sistema vigente com entrevistas e trabalho de campo. Deste modo, através dos relatos adquiridos nas entrevistas e dos materiais pedagógicos que a própria Escola utiliza foi proporcionado um enriquecimento de informaçôes, em que através dessas fontes pôde-se conhecer a história do acampamento e da Escola e como estấo atualmente, assim, relacionando com as análises das pesquisas bibliográficas para chegar no alcance dos objetivos da pesquisa.

Joaquim Nabuco e, depois, Caio Prado Jr. apontaram a necessidade da democratização da propriedade da terra como condição para o desenvolvimento do país. Prado Junior, em artigos publicados no começo da década de 1960, retomava o tema problematizando as políticas que estavam sendo implementadas em São Paulo e depois no país após o golpe de 1964, "visando uma reforma agrária para um suposto processo socioeconômico que significaria, assim se predestina, a transição de 'restos feudais' ou 'pré-capitalistas', para uma nova etapa capitalista e progressista" (1979, p. 9).

Trata-se de um contexto em que o modelo dominante de desenvolvimento da estrutura agrária no Brasil é excessivamente focado na agricultura capitalista patronal, logo, pautado no latifúndio, na monocultura de commodities e, não raro, no trabalho em regime escravo. Tal modelo tem como paradigma a modernização conservadora, gerando, dentre outros problemas, a expulsão dos camponeses da terra. Dessa forma, como caracteriza Guimarães (1977 apud PIRES; RAMOS, 2009), a estratégia desse modelo difere do da reforma agrária, tendo por objetivo a expansão da produção agropecuária mediante a renovaçáo tecnológica, sem que se tenha uma alteraçáo na estrutura agrária. Sobre isso, lembrou Tavares: "[as] transformaçôes das bases técnicas e econômicas, a terra e a riqueza 
continuaram sendo concentradas por força dos novos interesses agroindustriais, da expansão da fronteira e dos interesses agrários tradicionais" (1996, p. 5).

Novas fronteiras agrícolas sentiram o efeito dessa política, como é o caso do chamado Norte Pioneiro do Paraná, com consequências sociais importantes, parte do quadro geral do capitalismo brasileiro.

\section{PROPRIEDADE E POSSE DA TERRA}

No Brasil, o capitalismo adquiriu um caráter rentista, pois o seu desenvolvimento se faz principalmente através da fusão em uma mesma pessoa do capitalista e do proprietário de terra. Apesar de ser um processo cuja origem tenha se dado na escravidáo e principalmente na passagem do trabalho escravo para o trabalho livre, foi na segunda metade do século XX que essa fusão ampliou-se significativamente, quando, após 1964, os militares procuraram soldar essa aliança política. Dessa maneira, a chamada modernização da agricultura não atuou no sentido da transformação dos latifundiários em empresários capitalistas, mas, ao contrário, transformou os capitalistas industriais e urbanos, sobretudo do Centro-Sul do país, em proprietários de terra, em latifundiários. (OLIVEIRA, 2005).

Por conseguinte, essa transformação dos capitalistas industriais em latifundiários gerou uma concentração de renda e de terras nas mãos de poucos. Quem já tinha o capital passou a tê-lo em demasia, quem não tinha o capital foi expulso da terra ou passou a trabalhar sob condições precárias, uma vez que a mão de obra se torna mais barata, visto que a tecnologia e as máquinas suprem algumas tarefas humanas, além do fato de que o trabalhador do campo não tem muitas escolhas, pois precisa ter um sustento.

Essa concentração das terras nas mãos de poucos se torna mais clara ao se analisar as estatísticas do Instituto Nacional de Colonização e Reforma Agrária (INCRA). No ano de 1972, o número total de imóveis era de 3.387.173, e as grandes propriedades - os latifúndios - representavam somente 1,5\%, com 50.548 imóveis. No entanto, ocupavam 51,4\% da superfície total, ou seja, 193.749 .742 ha de uma área com 370.275.187 ha. Na década de 90, quando as lutas pela reforma agrária se intensificaram e o Estado precisou responder com políticas públicas de assentamentos fundiários, a conjuntura da concentração fundiária e desigualdade ainda era a mesma. Em 1998, 57.881 imóveis com mais de 1000 ha, de um total de 3.587.987 imóveis rurais, continuavam ocupando 52,9\%, ou seja, 216.824.528 ha de uma área total de 415.570 .812 ha. Em contrapartida, as pequenas propriedades, com menos de 100 ha, representavam 85,3\% dos imóveis rurais, ou seja, 3.061 .525 imóveis, e ocupavam uma área de $16,5 \%$ da área total, ou seja, 68.674.638 ha (OLIVEIRA, 2005). Além do mais, o capitalismo moderno se desenvolve necessariamente de maneira desigual, combinada e contraditória. Paulo Alentejano (2012, p. 479) diz que:

[...] a modernização produziu a ampliação da concentração da propriedade, da exploração da terra e da distribuição regressiva da renda, ou seja, ampliou a desigualdade no campo brasileiro, ao permitir que os grandes proprietários se apropriassem de mais terras e de mais riquezas em detrimento dos trabalhadores rurais, dentre os quais avançou a proletarização e a pauperização. 
Outro exemplo de manutenção da desigualdade no campo brasileiro ocorreu com o Golpe de 1964, quando as lutas populares sofreram violenta repressão. Nesse mesmo ano, o presidente-marechal Castelo Branco decretou a primeira Lei de Reforma Agrária no Brasil: o Estatuto da Terra ${ }^{15}$. Elaborado com uma propagada visão progressista, propondo mexer na estrutura fundiária do país, ele jamais foi implantado e se configurou como um instrumento estratégico para controlar as lutas sociais e desarticular os conflitos por terra. Em 1985, em meio ao clima da campanha 'Diretas já, o MST realizou seu primeiro Congresso Nacional, em Curitiba, no Paraná, cujas palavras de ordem era: 'Ocupação é a única solução'.

Neste mesmo ano, o governo Sarney aprova o Plano Nacional de Reforma Agrária ${ }^{16}$, que tinha por objetivo dar aplicação rápida ao Estatuto da Terra e viabilizar a Reforma Agrária até o fim do mandato do presidente, assentando 1,4 milhão de famílias. Porém, mais uma vez a proposta de Reforma Agrária ficou apenas no papel. Os artigos 184 e 186 da Constituição brasileira de 1988 referem-se à função social da terra e determina que, quando ela for violada, a terra seja desapropriada para fins de Reforma Agrária (OLIVEIRA, 2005).

Relacionando o modo desigual e combinado pelo qual o capitalismo vem se desenvolvendo ao trabalho no campo, é válido mencionar que a atuação do modelo capitalista se desenvolve na direção da inserção do trabalho assalariado no campo. Nesse ínterim, é possível entender, analisando a situação dos trabalhadores rurais que foram expulsos da terra e se tornaram trabalhadores livres, ou melhor dizendo, trabalhadores assalariados, que o capital está sempre do lado dos capitalistas industriais e latifundiários.

Ademais, ainda se pode relacionar que a modernização no campo é conservadora, uma vez que faz prevalecer a dominância do capital, que está nas mãos dos industriais através do domínio das terras de proprietários que não possuíam capital suficiente para acompanhar essa modernização no campo. Assim, esses capitalistas industriais obtiveram maior renda e o trabalhador rural foi lançado como livre e assalariado, obtendo um trabalho precário no campo ou na cidade. Nesse sentido descrevem Pires e Ramos (2009, p. 419):

[...] o uso de insumos industriais nas unidades de exploração agropecuária retirava da terra aqueles proprietários rurais que não conseguiam modernizarse, lançando-os como mão-de-obra livre aos mercados de trabalho capitalistas. Desta feita, a força de trabalho e a terra tornaram-se abundantes no país e não criaram obstáculos ao desenvolvimento industrial, uma vez que a agropecuária exerceu suas funçóes no modelo de substituiçấo de importaçóes.

Como supracitado, o capital está vinculado aos capitalistas industriais, urbanos e latifundiários, por isso o desenvolvimento do capitalismo é desigual e combinado, seguindo uma lógica para a burguesia (todos que detém os meios de produção) se manter dominante em relação ao poder e ao capital. Trata-se de um ciclo. Essa lógica do desenvolvimento capitalista no mundo é exemplificada, na visão do geógrafo britânico David Harvey, da seguinte maneira:

15 Lei N. 4.504, aprovada em 30 de novembro de 1964.

16 Decreto $\mathrm{N}^{\circ}$ 91.766, aprovado em 10 de Outubro de 1985. Apresentado pelo Ministério da Reforma e do Desenvolvimento Agrário - MIRAD, para o período de 1985/1989. 
[...] se você olhar para o histórico da dinâmica do capitalismo, há diferentes formas pelas quais ele se desenvolve. É um sistema [...] orientado para o crescimento, então ele sempre tem que buscar formas de crescer. Dentro da história do capitalismo já vimos várias formas de seu desenvolvimento, mas é um pré-requisito que ele sempre precise crescer. No [...] início do século 20 , ele crescia principalmente através da expansão global, com a construção de ferrovias que conectava o mundo geograficamente. Após isso, vimos como o crescimento se concentrou principalmente na urbanização, no crescimento urbano. Então você sai de uma situação [...] onde aproximadamente $7 \%$ da população mundial vivia em cidades, para o final do mesmo século, quando mais de $50 \%$ da populaçáo mundial é urbana [os trabalhadores rurais expulsos da terra que náo se tornaram assalariados no campo migram para os centros urbanos em busca de trabalho e melhores condiçóes de vida]. Deste modo, cada vez mais capital foi usado na construção das cidades, e desde os anos 2000 isso se intensificou ainda mais. [...] Acredito que o capitalismo sempre foi agressivo, acho que ele nunca foi "não agressivo". [...] Entáo, como grande resposta à grande crise financeira de 2007-2008, eles escolheram ajudar os bancos e deixar que as pessoas perdessem suas propriedades ao invés de ajudar as pessoas a permanecer em suas casas, o que poderiam ter feito. Isso levou a uma gigantesca transferência de capital da populaçáo de baixa renda para as grandes instituiçóes financeiras [fica evidente que as instituiçóes financeiras, as quais o capital está ao lado, obtém cada vez mais uma maior renda, enquanto a grande massa da população que não se enquadra nessa burguesia obtém cada vez mais uma menor renda, ou seja, novamente pode-se afirmar que a renda (e as terras) estáo concentradas nas máos de poucos]. (HARVEY, 2016, n.p.).

No que se refere ao atual modelo hegemônico de desenvolvimento agrário no país, é notável a presença predominante de commodities (em inglês, mercadorias). Sendo as commodities mercadorias, como minérios e gêneros agrícolas, são produzidas em grande escala e comercializadas em nível mundial, possuem preços que são definidos pelo mercado internacional. Também são caracterizadas por serem, geralmente, matéria-prima. De acordo com o que conceitua Porto-Gonçalves (2004), o mercado mundializado de commodities, como o mercado de grãos, estabelece à agricultura um alto padrão técnico-científico, de modo que a torna exageradamente dependente do capital. Diante disso, observa-se que, suprimida a terra, os inseticidas, fertilizantes, herbicidas, as máquinas e sementes são os elementos com maior peso na estrutura de custos por hectare, e, assim sendo, a expansáo do cultivo de grãos vem acompanhada por novas tecnologias (tratores-computadores, plantio direto e transgênicos) que diminuem os custos do trabalho (diminuiçấo significativa do trabalhador na produção) por um aumento da concentraçáo fundiária, de modo que o desenvolvimento desse modelo agrário-agrícola tem como fator decisivo essa disponibilidade de terras.

É válido apontar que os fazendeiros criadores de gado até os anos 60 permitiam aos camponeses a coleta de frutos, "o fazendeiro podia ser proprietário da terra, mas não do babaçu" (PORTOGONÇALVES, 2004, p. 18). Porém, com a expansão do agronegócio, os grandes empresários tiveram uma maior apropriaçáo dos recursos naturais. Nesse processo de expansão se perdeu diversidade cultural, biológica e várias formas de propriedade que não fosse propriedade privada (que priva a sociedade do poder de decisão a respeito do uso dos recursos naturais). Em relação a esse atual modelo agrário-agrícola, é importante compreender que: 
[...] esse modelo agrário-agrícola [...] que se apresenta como o que há de mais moderno sobretudo por sua capacidade produtiva, na verdade, atualiza o que há de mais antigo e colonial em termos de padrão de poder ao estabelecer uma forte aliança oligárquica entre (1) as grandes corporaçóes financeiras internacionais, (2) as grandes indústrias-laboratórios de adubos e de fertilizantes, de herbicidas e de sementes, (3) as grandes cadeias de comercialização ligadas aos supermercados e farmácias e (4) os grandes latifundiários exportadores de grãos. (GONÇAVES, 2004, p. 25).

Pode-se assim perceber que, além da concentração fundiária e de capital, o modelo hegemônico atual da agricultura, por colocar elevado capital, impede a democratização do modelo. Há também uma diminuição da mão de obra empregada e na participação do trabalho na distribuição da renda na produção como um todo. $\mathrm{Na}$ realidade, compensa-se a queda de preços dos produtos agrícolas com uma excessiva concentração de capital, assim, um setor como o da produção de alimentos, se desloca para as máos de poucas empresas transnacionais.

É um paradoxo, uma vez que se coloca em risco (e nas mãos de poucos, não focado na alimentação e sim na geração de riquezas para essas empresas) um setor da atividade humana cujo objetivo era justamente o da produção de alimentos como uma segurança alimentar. Dessa forma, a fome não é causada pela falta de alimentos, mas sim pelo modo como os alimentos são produzidos e distribuídos (PORTO-GONÇALVES, 2004). A luta pela terra é a afirmaçáo da frase do escritor Oswald de Andrade (1928), "a posse contra a propriedade", pedra de toque do direito antropofágico.

Nesse ínterim, um ponto relacionado a essa agricultura convencional que deve ser evidenciado é a questão do uso de agrotóxicos. Bombardi (2011, p. 1-2 e 6) alega que:

O Brasil, como é sabido, alcançou em 2009 o primeiro lugar no ranking mundial de consumo de agrotóxicos, embora não sejamos, como também é sabido, o principal produtor agrícola mundial [...] A expressão monopólio, neste caso, aparece mais vívida do que nunca: Estados Unidos, Suíça e Alemanha, juntos, através de suas empresas, controlam $70 \%$ da venda de agrotóxicos no Brasil [...] A venda mundial de agrotóxicos (em dólares) teve um acréscimo de 53,8\% no período de 1990 a 2008. Em 1990 ela envolveu cerca de 26 bilhóes de dólares e, em 2008, este valor saltou para 45 bilhóes de dólares.

O Brasil é atualmente o segundo maior exportador de soja e milho e o maior exportador de açúcar e álcool, portanto, a expansão desses cultivos, dessas commodities, é um dos fatores que explica o aumento no consumo de agrotóxicos no país. Nesse segmento, o processo de subordinação da renda da terra no Brasil ao capital monopolista internacional, através da compra e aplicaçáo de agrotóxicos, está sendo acompanhado por um grave problema na saúde pública que as intoxicaçóes por agrotóxicos. No período de 1999 a 2009 encontra-se notificados pelo SINITOX (Sistema Nacional de Informaçóes Tóxico- Farmacológicas - Ministério da Saúde/FIOCRUZ) cerca de 5.600 intoxicaçóes por ano no país, o que equivale a uma média de 15,5 intoxicaçóes diárias, ou uma a cada 90 minutos (BOMBARDI, 2011).

Esses agrotóxicos muitas vezes ainda são vistos como algo bom, que irá acabar com as "pragas" nas plantações, porém, se eles fossem "defensivos agrícolas", como são chamados, não seriam usados como um meio para o suicídio. 
No período representado [...] 1999 a 2009 [...] foram notificadas 25.350 tentativas de suicídio através do uso de agrotóxicos, isto significa uma média de 2.300 tentativas de suicídio por ano, ou seja, uma média de seis tentativas de suicídio por dia, com a utilizaçáo de agrotóxicos. Evidentemente que uma parte destes casos de intoxicação por agrotóxicos levou à morte das vítimas intoxicadas [...] (BOMBARDI, 2011, p.10)

Da mesma maneira, sobre os agrotóxicos e o atual modelo de desenvolvimento econômico, Pessoa e Rigotto (2012) alertam que os agrotóxicos utilizados no agronegócio geram graves problemas de saúde ao trabalhador no campo e grandes danos para o meio ambiente, sendo que essa exposição cotidiana aos agrotóxicos ocorre sem nenhum cuidado dos órgãos públicos. Dessa forma, percebe-se que a saúde da população e a preservação do meio ambiente estão debilitadas devido aos interesses do mercado, que possuem uma artimanha legislativa para manter esse ciclo econômico de desigualdade e exploração, onde o lucro é prioridade, e a preservação da saúde humana e do meio ambiente não tem espaço algum.

Por fim, entende-se que o tão falado agronegócio não está produzindo os alimentos que chegam à mesa dos brasileiros (esses alimentos são, geralmente, decorrentes dos pequenos produtores), e a riqueza que ele gera com as exportaçóes das commodities está nas mãos das grandes empresas. Ademais, os agrotóxicos usados nas plantaçóes beneficiam demasiadamente os seus produtores, enquanto populaçóes, como a do Brasil, que consomem e são expostas a quantidades gritantes desses agrotóxicos estáo sendo afetadas por eles, na maioria das vezes, sem se dar conta do veneno e do perigo a que são expostas.

Atualmente, transtornos como a depressão e a ansiedade estão aumentando na sociedade. Claramente, os agrotóxicos não são o único fator contribuinte para o aumento desses transtornos, no entanto, não se pode negar que um país cuja mídia propaga que o "agronegócio é tudo" se exclua essa hipótese da ligação entre o aumento da exposição a agrotóxicos e o aumento desses transtornos. Além, de que, quando se come algo proveniente desses grãos (ou até mesmo de produtos de pequenos produtores, afinal, mesmo os que não o utilizam estáo sujeitos à poluição, ao alastramento desses venenos), mesmo que seja aos poucos, a pessoa está se envenenando e prejudicando a saúde. Portanto, cultiva-se desinformação ao afirmar que "agro é vida".

\section{A LUTA PELA TERRA: MST E CPT}

É importante ressaltar que as transformaçôes de uma agricultura camponesa para uma agricultura capitalista geraram resistências contra esse modelo hegemônico capitalista, patronal. Forte exemplo disso é o Surgimento dos Trabalhadores Rurais Sem Terra (MST), que possuem como objetivos principais a luta pela terra, por uma Reforma Agrária, por uma sociedade mais justa e fraterna e por um desenvolvimento sustentável17 5quanto ao uso dos recursos naturais.

Nesse contexto do desenvolvimento excludente do sistema capitalista, o MST surge em consequência e em resistência a esse sistema. Os camponeses, expulsos do campo e impedidos do acesso à terra, passaram, de forma articulada, a contestar a estrutura fundiária vigente, a questionar a ordem social. Organizados a partir das Comunidades Eclesiais de Base (CEBs) 18 das pastorais sociais, passaram a ocupar as grandes propriedades improdutivas. 
Herdeiros das lutas pela terra, o Movimento dos Trabalhadores Rurais Sem Terra (MST) nasceu oficialmente em 1984, no $1^{\circ}$ Encontro Nacional do Movimento dos Trabalhadores Rurais Sem Terra, ocorrido em Cascavel, no Paraná, entre os dias 20 e 22 de janeiro, tendo a participação e o apoio da Comissão Pastoral da Terra (CPT) e de alguns sindicatos de trabalhadores rurais, herdeiros de lutas pela terra no Brasil.

É válido mencionar que a CPT é uma organização pastoral vinculada à Igreja Católica e a outras igrejas cristãs, sendo que realiza suas ações juntamente com mulheres e homens do campo, incluindo toda sua diversidade, os agricultores familiares, os pequenos proprietários, os agricultores sem-terra, ribeirinhos, quilombolas, trabalhadores e trabalhadoras rurais assalariados. A CPT surgiu, em 1975, com a urgência da realidade da Amazônia, no período da Ditadura Militar, em que grandes bancos e empresas adquiriram extensas áreas de terras com o objetivo de conseguir os recursos dos incentivos fiscais oferecidos para os que se dispusessem a investir no desenvolvimento da região. Essas áreas eram consideradas inabitadas, mesmo se tivessem a presença de aldeias indígenas, e assim ocorreram a invasão dos territórios indígenas.

Nesse contexto, a CPT se articulou não só na Amazônia, mas em quase todas as regióes do país, "contribuindo para articular as iniciativas das comunidades camponesas, ao mesmo tempo em que busca envolver toda a sociedade na luta pela terra e na terra" (CANUTO, 2012, p. 130). Ainda se tratando do apoio de setores da Igreja, Floresta (2006, p.19) afirma que "no Brasil, a luta pela terra quase sempre esteve ligada à Igreja que, ao longo do século XX, teve um papel fundamental nos conflitos, sendo, muitas vezes, legitimadora da repressão, justificando-a. No entanto, foi através da ação ou apoio de setores da Igreja que os camponeses construíram sua resistência”.

A gênese do MST teve um período de gestação. Bernardo Mançano Fernandes (2012) explica que este período se iniciou ainda na década de 1970, com lutas pela terra ocorrendo no Rio Grande do Sul, Santa Catarina, Paraná e Mato Grosso do Sul. A territorialização do Movimento pelas regiôes brasileiras, a partir de entáo, permitiu a conquista de milhares de assentamentos rurais, representando o renascimento dos movimentos camponeses no Brasil, uma vez que no período da Ditadura Militar (1964-1985), havia repressão a esses movimentos. Fernandes (2012) fala também sobre os conflitos que se multiplicaram com o desenvolvimento do agronegócio, citando o massacre de Eldorado dos Carajás ocorrido no Pará, em 1996, e o assassinato de Valmir Motta de Oliveira, conhecido como Keno, em 2006, no Paraná, durante a ocupação pela Via Campesina de uma área experimental de produção de sementes transgênicas da empresa suíça Syngenta.

O MST organiza sua luta pela realização da Reforma Agrária e por uma sociedade mais justa e sustentável, assim suas açóes contribuem para o desenvolvimento dos territórios camponeses e do país. Porém "enquanto os militantes do MST trabalham nos assentamentos e nos acampamentos para melhorar as condiçóes de vida, são ameaçados constantemente pelo agronegócio que, por meio da expansão das monoculturas, [...] procura se apropriar dos territórios camponeses, conquistados na luta pela terra [...]" (FERNANDES, 2012, p. 499). Cabe ressaltar que os artigos 184 e $186 \mathrm{da}$ Constituição brasileira de 1988, referem-se à função social da terra e determina que, quando ela for violada, a terra seja desapropriada para fins de Reforma Agrária. Sobre esta questão do capitalismo e do agronegócio colocarem o lucro, a propriedade como prioridade, e o MST colocar o ser humano como prioridade, Floresta (2006, p. 12) assegura que:

[...] seguramente, necessitamos de uma humanidade capaz de compreender que a libertação não consiste no pleno desenvolvimento de necessidades e faculdades voltadas para a obtenção/satisfação através do Ter. Isso significa uma quebra de 
padrôes culturais, uma mudança de conceitos, inversão de valores, de postura diante de uma determinada realidade. O MST, ao propor uma inversão de prioridades e colocar a vida e o trabalho como anteriores ao direito de propriedade, no nosso entender, faz isso.

O processo histórico onde a terra e, consequentemente, os meios de produção ficam nas mãos de poucos é melhor explicado ao compreender a relaçáo de opressor (os detentores desses meios de produção) e de oprimido (a maioria das pessoas que detém apenas sua força de trabalho) dentro do sistema capitalista do qual falou Karl Marx no século XIX. Assim, o MST utiliza dessa compreensão para contestar a estrutura do Estado do sistema capitalista, onde "a origem do Estado reside na emergência da propriedade privada, quando um dado grupo social apropriou-se daquilo que a todos pertencia, subordinando os demais e transformando-os em força de trabalho" (CALDART et al., 2012, p. 349).

A partir do materialismo histórico, realiza-se um estudo dos valores e fins que constituem a consciência dos seres humanos de uma época, observando que o que se tem hoje é reflexo de um processo histórico em que se teve açóes de homens agindo de acordo com seu interesse onde se apropriaram do meio ambiente. Marx afirma que "os homens fazem sua própria história, mas não a fazem como querem; não a fazem sob circunstâncias de sua escolha e sim sob aquelas com que se defrontam diretamente, legadas e transmitidas pelo passado" (1978, p. 329).

Cabe ressaltar, que a classe dos detentores dos meios de produçáo utiliza de meios para naturalizar esse processo histórico de dominação, no qual essa classe do opressor explora a do oprimido, como a educação tradicional capitalista "cujo centro é transmissão de conhecimentos, atitudes, valores e comportamentos para a socialização submissa, para o mercado de trabalho e para a naturalização, a aceitação e a reprodução da sociedade dividida em classes" (PALUDO, 2012, p. 280). Desse modo, o MST, enquanto Movimento de resistência, utiliza da Educação Popular, dentro das Escolas Itinerantes, no caso dos acampamentos, que visam a educaçáo crítica de estudantes conscientes de seus direitos, para transformar a realidade social. Assim, cabe destacar que:

Se por um lado as classes que detêm o poder econômico contam com os meios de comunicação de massa para difundir os valores e idéias neoliberais e buscam criar indivíduos apolíticos e atomizados, os movimentos sociais de luta pela terra, por outro lado, contam com milhares de líderes, ativistas, militantes e publicaçôes para criar uma cultura alternativa baseada na solidariedade. (FLORESTA, 2006, p. 12).

Os Movimentos Sociais realizam açóes sociais coletivas de caráter sociopolítico e cultural que viabilizam formas distintas de a população se organizar e expressar suas demandas. Essas formas adotam diferentes estratégias que variam da simples denúncia, passando pela pressão direta (mobilizaçôes, marchas, passeatas, etc.), até as pressôes indiretas. Atualmente, os principais movimentos sociais atuam por meio de redes sociais.

A experiência da qual são portadoras não advém de forças congeladas do passado - embora estas tenham importância crucial ao criar uma memória que, quando resgatada, dá sentido às lutas do presente. A experiência recria-se cotidianamente, na adversidade das situaçóes que enfrentam. Os movimentos realizam diagnósticos sobre a realidade social, constroem propostas, organizam 
açôes coletivas que agem como resistência à exclusão e lutam pela inclusão social. As características básicas dos movimentos sociais podem ser descritas da seguinte maneira: possuem identidade, têm opositor, e articulam ou fundamentam-se em um projeto de vida e de sociedade (GOHN, 2011).

\section{EDUCAÇÃO POPULAR E EDUCAÇÃO}

A Educação Popular, surgiu no início dos anos de 1960, em contraposição ao modelo de educação tradicional, sendo que esta origem decorre do modo de produção da vida em sociedade no capitalismo, emergindo no Brasil a partir da luta das classes populares na defesa de seus direitos. A Educação Popular tem suas raízes nas experiências históricas de enfrentamento do capital pelos trabalhadores na Europa, no pensamento pedagógico socialista, na teoria de Paulo Freire, na Teologia da Libertação, enfim, em múltiplas referências combinadas com experiências concretas. Desta forma, com a Educação Popular, "estabelece-se [...] o vínculo entre educação e política, educação e classe social, educação e conhecimento, educação e cultura, educação e ética, e entre educação e projeto de sociedade" (PALUDO, 2012, p. 282).

Assim sendo, a Educação Popular, ganha o sentido de ser uma educação do povo para o povo, superando o sentido de ser uma educaçáo das elites para o povo, com o intuito de controlar. Como afirma Saviani (2013, p. 317):

[...] a expressão "educação popular" assume, então, o sentido de uma educação do povo, pelo povo e para o povo, pretendendo-se superar o sentido anterior, criticado como sendo uma educação das elites, dos grupos dirigentes e dominantes, para o povo, visando a controlá-lo, manipulá-lo, ajustá-lo à ordem existente [...] esses movimentos tinham em comum o objetivo da transformação das estruturas sociais e, valorizando a cultura do povo como sendo a autêntica cultura nacional.

Para esclarecimento de termos, é necessário afirmar que a Educação do Campo está na Educação Popular, ademais, a Educação do Campo não é só do MST, ela abarca os indígenas, os quilombolas, dentre outros grupos. Assim cada povo estrutura a Educação do Campo sob sua realidade. Paludo (2012, p. 283) ainda menciona que no Brasil "a Educação do Campo pode ser identificada como uma das propostas educativas que resgata elementos importantes da concepção de Educação Popular e, ao mesmo tempo, os ressignifica, atualiza e avança nas formulaçóes e práticas direcionadas a um público específico".

Como alternativa às práticas e às teorias educacionais liberais e tradicionais, que estão a serviço da manutenção da ordem política, da exploração da força de trabalho e do domínio cultural, a Educação Popular está vinculada à transformação social. Essa proposta de educação do Movimento liga-se, também, à Escola Unitária de Gramsci que visa a formação humana e técnica entrelaçando trabalho, ciência e cultura, o que revela, assim, uma inovação do mundo social e material. (RAMOS, 2012).

O MST vem desenvolvendo um novo modo de fazer política. Parece-nos que o Movimento acatou as premissas gramscianas de que a maior parte dos organismos culturais assegura a transmissáo de uma concepçáo de mundo que 
permite a hegemonia da classe dominante, e que pensar a mudança da sociedade passa necessariamente por construir uma prática educativa que seja uma contra ideologia [...] (FLORESTA, 2006, p. 86).

Marise Ramos (2012) esclarece que Antonio Gramsci, nos anos de 1930, na Itália, propôs a Escola Unitária, com o fundamento de romper a divisão entre trabalho manual e intelectual estabelecida pela divisão da sociedade em classes. O trabalho possui aqui um princípio educativo, não tendo um fim profissionalizante na escola. A organização dos conteúdos de ensino é orientada pela integração entre trabalho, ciência e cultura.

O acampamento Valmir Motta de Oliveira e a escola itinerante Valmir Motta de Oliveira, em Jacarezinho-PR

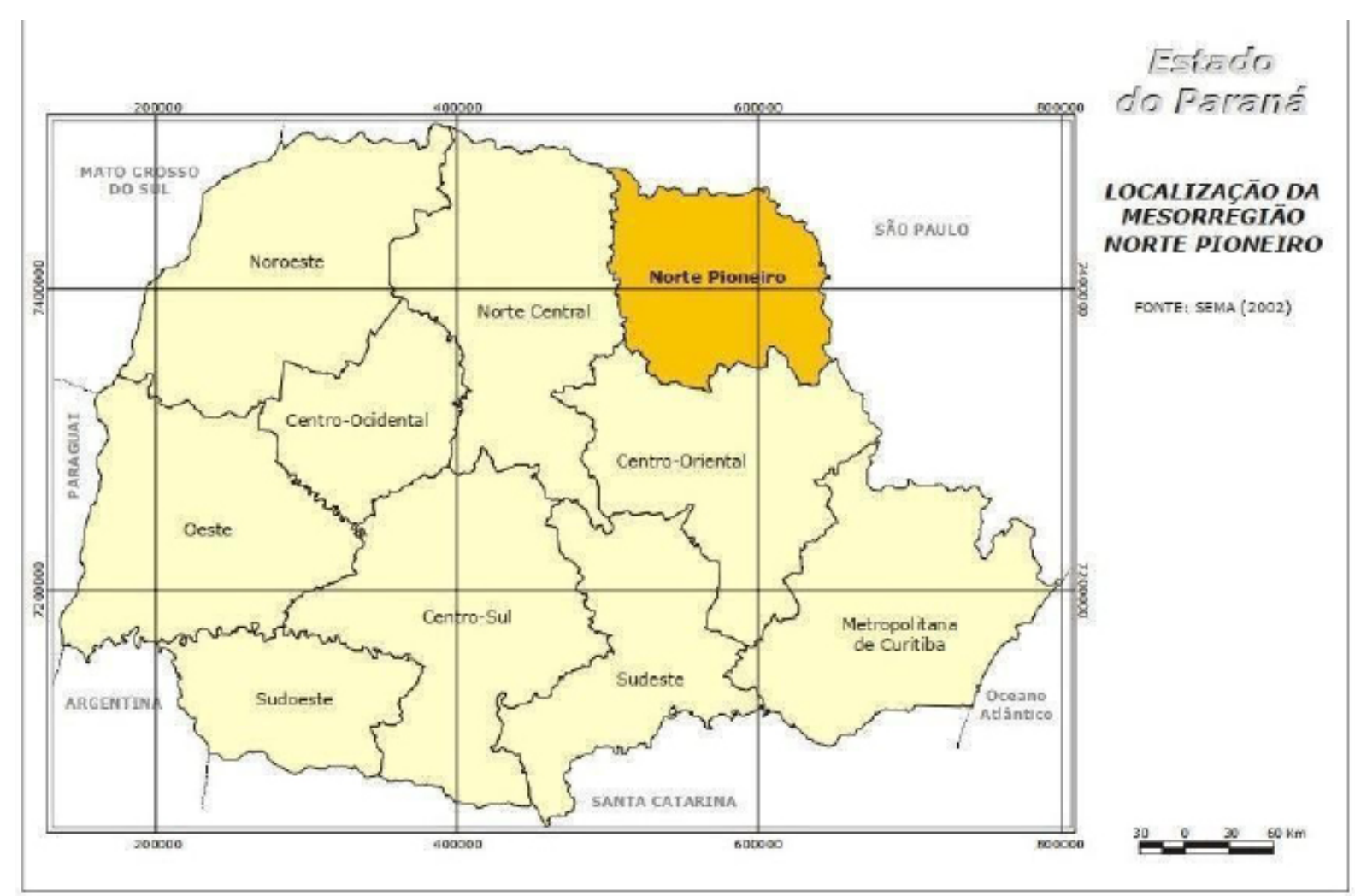

Imagem 1: As mesorregiões do Paraná e o Norte Pioneiro. Fonte: IPARDES, 2004, p. 6.

Jacarezinho, cidade de fronteira com Sáo Paulo, foi porta de entrada para a expansão da agricultura e das estruturas sociais estabilizadas em outras regióes há mais de um século (1890), e no século XX desenvolveu-se muito em função da expansão das lavouras paulistas (SELONK, 1999). Assim, as primeiras tentativas de colonização conhecidas datam do século XIX, por volta de 1898 . Apontada como um dos primeiros polos de desenvolvimento agrícola do Estado, sua colonização foi realizada por fluminenses, paulistas e mineiros. Sua riqueza maior provém do setor agropecuário e de prestação de serviços.

Cidade de uma região antes chamada de "Norte Velho" pelos novos "desbravadores" da região de Londrina, foi denominada posteriormente de "Norte Pioneiro", expressão comumente utilizada. A saga dos pioneiros é uma narrativa ainda viva na memória da cidade. Aimone, professor de História desde a década de 1930, assim narra a "fundação" do município. Por determinação do 
patriarca, Antonio Alcântara da Fonseca Guimaráes, o neto Antonio de Fonseca Neto organiza sua comitiva e chega, depois de 20 dias, à margem do Rio Paranapanema: "A esperada notícia alegrou o patriarca. A demora foi pequena. Os preparativos da mudança foram acelerados e dias depois com todos os seus familiares e mais empregados e amigos como também grande número de escravos, compondo a caravana mais de 254 pessoas, fora os escravos, não faltando o médico [...] e o padre [...]" (AIMONE, 1991, p. 4). Tal situação encontra em Perrone-Moises (1990, p. 98-9) uma apropriada definição: "[...] a transformação do velho em novo, do alheio ao próprio, do dejà vu em original. Por reconhecer que originalidade nunca é mais do que uma questão de arranjo novo".

Localizada na região do nordeste do estado do Paraná, surgiu como parte da expansão econômica cafeeira em direção ao interior. A exploração da cafeicultura produziu riquezas para proprietários, e provocou a destruição das florestas nativas. As terras do estado que depois se tornariam cafezais estavam cobertas pela Mata Atlântica. (DEAN, 1996).

No início do século, a maior cultura era a do café. Posteriormente, houve a substituição do café pelas lavouras de cana-de-açúcar, indústria de açúcar e álcool e pastagens. Novos produtos com cotaçáo no mercado externo e interno como a soja, o algodão e o trigo, avicultura e suinocultura vieram a partir da década de 70, sobretudo após a Geada Negra que atingiu o Norte Pioneiro, em julho de 1975. A dependência do $1^{\circ}$ setor persiste e, ainda hoje, grande parte da economia gira em torno da agropecuária, mais precisamente das usinas de cana-de-açúcar instaladas no município.

A cidade foi elevada à condiçáo de Município por meio da Lei n. ${ }^{\circ 522}$, de 2 de abril de 1900 , recebendo inicialmente o nome de Nova Alcântara. Em 03 de março de 1903, através da Lei n. ${ }^{\circ} 471$, recebeu o nome de Jacarezinho. Referência por sua universidade, a partir das antigas faculdades, além de escolas e atividades culturais, Jacarezinho é considerada a capital estudantil da região. Geograficamente localizada em um ponto de ligação rodoviária com as mais importantes cidades do Paraná e São Paulo, fica equidistante de Curitiba e da capital paulista - $400 \mathrm{~km}$.

O regime de colonato, no período da reestruturação e reforma conservadora da ditadura civil-militar, foi substituído pela mão-de-obra volante, conhecida como "boia fria" e os trabalhadores das grandes fazendas ocuparam as regiôes de habitaçóes e condiçóes precárias da zona urbana, na diáspora propiciada pela mecanização agrícola, servindo de braços para as usinas de cana-de-açúcar, indústria mais recente e dominante na regiáo, contexto inclusive determinante para a criação do MST e, no caso de Jacarezinho, o acampamento Valmir Motta de Oliveira.

O acampamento Valmir Motta de Oliveira localizado no município é parte das primeiras escolas que foram criadas no Paraná em um contexto de ocupaçôes intensas na expectativa da Reforma Agrária nos anos de 2003 e 2004. São Itinerantes porque acompanham a luta pela Reforma Agrária, possibilitando a escolarizaçáo dos trabalhadores do campo. Estáo inseridas em um acampamento onde a luta de classes é mais notória. Todavia, vale destacar que as Escolas Itinerantes são escolas que constituem a rede estadual pública de ensino e seus funcionamentos são aprovados e regulados pelo Estado, por meios dos Conselhos Estaduais de Educação. Portanto, as mesmas possuem vinculação legal a uma escola base que, geralmente, se localiza em um assentamento, sendo essa escola a base responsável por matrículas, acompanhamento pedagógico, além de gestão escolar.

O acampamento Valmir Motta de Oliveira se formou em 2006, com uma ocupação da fazenda Itapema que já tinha sido desapropriada pelo INCRA (Instituto Nacional de Colonização e Reforma Agrária). A fazenda Itapema, possui cerca de 500 ha. Em uma entrevista não estruturada, ocorrida no ano de 2018, a dirigente do acampamento mencionou que o processo da questáo jurídica da terra está complicado, pois o proprietário, já falecido, devia muito imposto e a família sempre recorre, processo este que se fosse finalizado, a terra poderia ser desapropriada, e se formaria 
um assentamento. Já em 2009, os integrantes do acampamento construíram o espaço da Escola Itinerante Valmir Motta de Oliveira, porém as aulas já tinham sido iniciadas em agosto de 2008 no casarão e nos galpóes do acampamento.

Em 2010, os educandos do Ensino Médio passaram a estudar na Escola Itinerante. A Escola possui em torno de 91 educandos.

Em entrevista, a dirigente disse que a Escola Itinerante busca ensinar a criança a partir da realidade deles, não deixando de seguir os conteúdos que são propostos no Currículo, formando cidadãos críticos, conscientes, que consigam intervir pelo bem de todos, pensando em um propósito maior. É válido destacar que em 2018 a Secretaria de Educação determinou que a escola base da Escola Itinerante Valmir Motta de Oliveira mudasse, deixando de ser a Escola de um assentamento, para ser a Escola de Marques dos Reis, que não é do Movimento e segue a educação escolar tradicional, assim dificultando ainda mais o desenvolvimento da proposta da Educação Popular.

A Escola Itinerante Valmir Motta de Oliveira insere a Educação Popular utilizando do pensamento de educadores como Paulo Freire e Moisey Pistrak, os quais afirmam que quem deve construir a nova escola são os educadores, junto com os educandos e suas comunidades. Assim sendo, a Escola Itinerante Valmir Motta de Oliveira possui uma gestão democrática, na qual os educandos, educadores e pais têm a oportunidade na escola de um tempo e espaço autônomos para que se encontrem e discutam variadas questôes, tomem decisóes no coletivo maior de gestáo da escola, permitindo que os estudantes, com a auto-organização, desenvolvam o exercício da autonomia.

Além do mais, a Escola em questáo, seguindo a organização das demais Escolas Itinerantes dos acampamentos e das escolas dos assentamentos, tem seu currículo organizado em Ciclos de Formação Humana, com os quais busca-se contrariar a lógica escolar excludente da seriação, baseando a organização do trabalho pedagógico numa perspectiva emancipatória. O I Ciclo é o da Infância na Educação Infantil, que compreende o atendimento a crianças de 4 e 5 anos de idade, com o trabalho unidocente.

O Ensino Fundamental organiza-se em três ciclos: o I Ciclo do Fundamental é o da Infância, no qual os educandos de 6, 7 e 8 anos de idade precisam construir o domínio da alfabetizaçáo; o II Ciclo é o da Pré-Adolescência, em que se tem a ampliação da alfabetização de educandos com 9, 10 e 11 anos de idade (a partir desse ano são atendidos de forma multidocentes); e o III Ciclo é o da Adolescência, em que o foco passa a ser a estruturação de conceitos, com os estudantes possuindo 12, 13 e 14 anos. Por sua vez, o Ensino Médio é o Ciclo da juventude na escola, e o foco passa a ser em como os conteúdos contribuem para entender o mundo onde vivem, as relaçóes com o mundo do trabalho, problematizando as inseguranças frente ao novo e às escolhas, sendo que neste ciclo os educando possuem 15, 16 e 17 anos.

A Escola referida se apresenta como um meio de dar elementos sobre a aprendizagem dos educandos através dos Pareceres Descritivos. Esses pareceres informam o que foi aprendido e o que ainda precisa ser. Assim, cada professor realiza um parecer sobre o resultado da aprendizagem e do desenvolvimento de cada estudante. Os pais e estudantes têm acesso a um documento descritivo com limites, necessidades e possibilidades que cada educando apresenta, ao invés de ter acesso a um boletim com médias aritméticas que pouco dizem. Na Escola Itinerante Valmir Motta de Oliveira são presentes, também, os Núcleos Setoriais, que é orientado por um educador em conjunto com educandos de diferentes idades, os quais realizam atividades aliadas aos conteúdos das disciplinas, vivenciando a teoria e a prática com açôes que seguem a auto-organização e a gestão da escola. Alguns Núcleos Setoriais da Escola são: Produção Agrícola, Registro e Memória, Comunicação e Cultura e Apoio ao Ensino. 
A Escola Itinerante Valmir Motta de Oliveira, utiliza o Plano de Estudos das Escola Itinerantes do estado do Paraná do ano de 2013. Este Plano de Estudos aborda, entre outras questóes, a Pedagogia do Movimento, que se constitui como uma reflexão específica sobre as matrizes pedagógicas postas em movimento na formação dos Sem Terra, tratando-a como um processo educativo que pode inspirar diferentes práticas educativas. Desta forma, essa pedagogia fundamenta e reafirma uma concepção de educação que não é hegemônica na história das teorias sobre educação, e que não está também na base de constituição da instituição escola. Porém, trata-se de uma concepção de base histórica, materialista e dialética para a qual é preciso considerar centralmente as condiçóes de existência social em que cada ser humano se forma. Não há formação da consciência fora da vivência das relaçóes sociais, e elas são históricas, como o são os objetivos formativos e todos os processos educativos.

No Plano de Estudos supracitado, há um item sobre a organização política da Escola, no qual apresenta, também, os Tempos Educativos, sendo que nem todos acontecem todos os dias e seu planejamento deve ser realizado em comum acordo com os educadores e os Núcleos Setoriais. Assim, no Plano de Estudos são sugeridos alguns Tempos. Como exemplo, pode-se citar alguns Tempos que são praticados na Escola Itinerante referida neste texto.

Um deles é o Tempo Abertura, que é um momento coordenado pelos Núcleos Setoriais da escola, em que a coletividade se encontra para vivenciar a mística. Ocorre a conferência dos núcleos e das turmas com as suas palavras de ordem, é entoado o hino, música ou mesmo são realizadas apresentaçóes previamente agendadas. Assim, podem ser realizadas homenagens, apresentaçáo dos símbolos da luta e o resgate da memória de lutas anteriores, sempre lembrando do porquê da luta do Movimento. E neste tempo, ainda, são feitos os informes necessários a cada dia, que é realizado, na Escola Itinerante Valmir Motta de Oliveira, antes do início das aulas ou antes do intervalo.

De igual maneira, pode-se mencionar o Tempo Leitura, que se organiza a partir das leituras planejadas para cada turma, portanto é um tempo organizado por turma (com suas especificidades e objetivos), visando construir o gosto e a disciplina pela leitura. Por sua vez, o Tempo Aula é o Tempo diário destinado à execução das disciplinas do planejamento curricular, conforme cronograma das aulas. Este tempo educativo está sob responsabilidade dos educadores e do Núcleo Setorial de Apoio ao Ensino. Prioritariamente, este tempo pode acontecer mesclado aos demais tempos educativos. Ademais, não se limita, em sua execução, ao conceito de "aula" normalmente utilizado na escola tradicional, podendo incluir excursóes, aulas- passeio, estudo de campo, entre outros.

Por fim, na entrevista semiestruturada com a professora de História da Escola, que é educadora do $6^{\circ}$ ano ao Ensino Médio, foi possível compreender alguns fatores que limitam o exercício da Educação Popular na Escola Itinerante referida. Um desses fatores é a imposição do Estado para atender à Grade Curricular (como exemplo, a mudança da escola base para uma escola de ensino tradicional, mencionada anteriormente). Outro fator é ter pouca hora- atividade para preparar uma aula que atenda a realidade desses estudantes. Também foi citado como fator limitante os professores que vêm do Estado e já carregam a educação tradicional, não se adaptando à Educação Popular e nem participando da luta contra as imposiçóes que vêm do Estado.

A professora expóe que nessa proposta de educação, parte-se da raiz do educando, de sua realidade social, e que a Educação Popular possui uma Pedagogia viva, em que os estudantes atuam como sujeitos ativos em seu processo de aprendizagem, interagindo diretamente neste processo, enquanto que a educação escolar tradicional possui uma pedagogia morta, em que os estudantes apenas recebem informações dos professores, sem significar e relacionar com as suas vidas e sem qualquer interação direta no seu processo de aprendizagem. Quanto à proposta de educação e às limitaçóes, a professora afirma que: 
Não deixa de seguir a grade, mas ela não é a prioridade, segundo a escola Florestan Fernandes, que é uma escola de base, de apoio do Movimento Sem Terra, e, nós temos que seguir por uma outra estrutura, entáo a gente tem que partir pela porção da realidade e não partir pelo conteúdo. Eu vou começar a estudar com eles, por exemplo, a Mesopotâmia, né, vou estudar o Egito, pro Movimento Sem Terra eu tenho que antes enxergar, entender o que tá acontecendo na comunidade, em termos de coletividade, em termos de ocupação da terra, então eu preciso entender isso, para daí em começar a incluir o conteúdo junto nisso. A gente faz o contrário, a gente parte do conteúdo e fica depois buscando algumas comparaçōes, porque a gente não tem tempo suficiente para fazer esse exame [...]”. (Em entrevista, 04/2019).

Sobre os estudantes da Escola Itinerante, a professora comenta que “[...] eles são bem sensíveis às causas sociais [...] eles não são de fácil lavagem cerebral, uma criança do Movimento Sem Terra quando vai para a cidade ela sofre muito, porque ela não acredita nem em meia dúzia do que é falado para ela" (Em entrevista, 04/2019).

\section{CONSIDERAÇÕES FINAIS}

Thompson referia-se à revolução industrial, mas, no Brasil, na ditadura militar, é possível utilizar a mesma reflexão: "o povo foi submetido, simultaneamente, à intensificação de duas formas intoleráveis de relação: exploração econômica e a opressão política” (THOMPSON, 2001, p. 23). O munícipio de Jacarezinho, na região nordeste do Paraná, é cenário da expansão agrícola, concentração de terra e modernização conservadora, características do capitalismo brasileiro, mas configura-se, também, como um local de luta pela terra, de constituição de uma escola democrática e, principalmente, as bases para a crítica e transformação da sociedade, a partir da luta de mulheres e homens do MST, a produção de uma outra história, afinal no mesmo nexo da exploração nasce a resistência. Ainda segundo Thompson (2001, p. 167):

Primeiro, no curso real das análises históricas e sociológicas (bem como as políticas), é de grande importância lembrar que os fenômenos sociais e culturais não correm atrás dos econômicos após longa demora; estão, na sua origem, imersos no mesmo nexo relacional. Segundo, ao passo que uma forma de oposição ao capitalismo se constrói sob o antagonismo econômico direto - resistência à exploração, seja como produtor, seja como consumidor -, outra forma é, exatamente, resistência à tendência inata do capitalismo a reduzir todas as relaçóes humanas às definiçóes econômicas (...).

Deste modo, compreendendo o acampamento Valmir Motta de Oliveira e a Escola Itinerante Valmir Motta de Oliveira como representantes do todo que é o MST (o maior e mais importante Movimento Social do mundo) entende-se o porquê de estarem onde estão e o que significam e representam para a sociedade, como representantes de uma mudança não só na estrutura agrária, mas de luta pelos direitos e pela preservação da natureza e da vida humana, além da proposta da Educação Popular que lutam para inserir em suas escolas, como contraponto à educaçáo tradicional do sistema capitalista. 
Durão, Mussi e Maranhão afirmam que "estas tensôes e dificuldades, próprias da busca de construção do novo no contexto do velho, não retiram a importância e mesmo urgência em gestar experiências educacionais e escolares que se contrapóem à ordem vigente" (2015, p. 160-161). Assim, abordam que mesmo com as limitaçóes e problemas que a Escola Itinerante possui, é inegável a importância dessa ação de inserir uma outra proposta de educação como crítica e resistência ao sistema capitalista.

\section{REFERÊNCIAS}

AIMONE, Thomaz. Jacarezinho. Jacarezinho, seus pioneiros desbravadores e os que labutam para o progresso desta terra [s.n.], 1991.

ALENTEJANO, Paulo. Modernização da Agricultura. In: CALDART, Roseli Salete; PEREIRA, Isabel Brasil; ALENTEJANO, Paulo; FRIGOTTO, Gaudêncio (Orgs.). Dicionário da Educação do Campo. 2. ed. Rio de Janeiro, São Paulo: Escola Politécnica de Saúde Joaquim Venâncio, Expressão Popular, p. 477-481, 2012.

ANDRADE, Oswald de. Manifesto Antropófago. Revista de Antropologia, ano I, n. I, p. 3 e 7, maio 1928b.

BOMBARDI, Larissa Mies. Intoxicação e morte por agrotóxicos no brasil: a nova versão do capitalismo oligopolizado. Boletim DATALUTA, USP, São Paulo. Artigo do mês Setembro. 2011.

CALDART, Roseli Salete; PEREIRA, Isabel Brasil; ALENTEJANO, Paulo; FRIGOTTO, Gaudêncio (Orgs.). Dicionário da Educação do Campo. 2. ed. Rio de Janeiro, São Paulo: Escola Politécnica de Saúde Joaquim Venâncio, Expressão Popular, 2012, 788 p.

CANUTO, Antonio. Comissão Pastoral da Terra (CPT). In: CALDART, Roseli Salete; PEREIRA, Isabel Brasil; ALENTEJANO, Paulo; FRIGOTTO, Gaudêncio (Orgs.). Dicionário da Educação do Campo. 2. ed. Rio de Janeiro, São Paulo: Escola Politécnica de Saúde Joaquim Venâncio, Expressão Popular, p. 128-133, 2012.

DEAN, Warren. A Ferro e Fogo: a história e a devastação da Mata Atlântica brasileira. Tradução Cid Knipel Moreira. São Paulo: Companhia das Letras, 1996.

DURÃO, Fabio Akcelrud; MUSSI, Daniela; MARANHÃO, Andréia Pagani (Orgs.). Marxismo: cultura e educação: contribuiçóes do VII Colóquio Internacional Marx Engels. 1. ed. São Paulo: Nankin, 2015. 168p.

FERNANDES, Bernardo Mançano. Movimento dos Trabalhadores Rurais Sem Terra (MST). In: CALDART, Roseli Salete; PEREIRA, Isabel Brasil; ALENTEJANO, Paulo; FRIGOTTO, Gaudêncio (Orgs.). Dicionário da Educação do Campo. 2. ed. Rio de Janeiro, São Paulo: Escola Politécnica de Saúde Joaquim Venâncio, Expressão Popular, p. 496-500, 2012.

FLORESTA, Leila. Escolas dos acampamentos/assentamentos do MST: uma pedagogia para revolução? Tese (Doutorado em Educação) - Programa de Pós-graduação da Faculdade de Educação da Universidade Estadual de Campinas. Campinas - SP, 210p. 2006. 
GOHN, Maria da Glória. Movimentos Sociais na Contemporaneidade. Revista brasileira de educação, v. 16, n. 47, p. 333-513, mai./ago., 2011.

HARVEY, David. "David Harvey: “O capital está sempre do lado da direita”". [Entrevista concedida a] Fania Rodrigues. Caros Amigos, 229 ed., n.p., 21 jun., 2016.

MARX, Karl. Manuscritos econômicos-filosóficos e outros textos escolhidos. Tradução de José Carlos Bruni et al. 2. ed. São Paulo: Abril, 1978. (Coleção Os pensadores - vol.: Marx).

OLIVEIRA, Ariovaldo Umbelino de. "Quem sabe faz a hora, não espera acontecer". O MST como movimento socioterritorial moderno. Revista USP, São Paulo, n.64, p. 156-172, dez./fev., 2005.

PALUDO, Conceição. Educação Popular. In: CALDART, Roseli Salete; PEREIRA, Isabel Brasil; ALENTEJANO, Paulo; FRIGOTTO, Gaudêncio (Orgs.). Dicionário da Educação do Campo. 2. ed. Rio de Janeiro, São Paulo: Escola Politécnica de Saúde Joaquim Venâncio, Expressão Popular, p. 280-284,2012.

PERRONE-MOISÉS, Leyla. Flores da escrivaninha. Cia das Letras, 1990.

PESSOA, Vanira Matos; RIGOTTO, Raquel Maria. Agronegócio: geração de desigualdades sociais, impactos no modo de vida e novas necessidades de saúde nos trabalhadores rurais. Revista Brasileira de Saúde Ocupacional [online], janeiro/junho. 2012. Disponível em: <http://www.scielo.br/pdf/rbso/v37n125/ a10v37n125.pdf>. Acesso em: 25 ago. 2019.

PIRES, Murilo José de Souza; RAMOS, Pedro. O termo modernização conservadora: sua origem e utilização no brasil. Revista Econômica do Nordeste, [S.I.], v. 40, n. 03, p. 412-424, jul./set., 2009.

PORTO-GONÇALVES, Carlos Walter. Geografia da riqueza, fome e meio ambiente: pequena contribuição crítica ao atual modelo agrário/agrícola de uso dos recursos naturais. Revista Internacional Interdisciplinar Intertheisis -PPGICH-UFSC. Florianópolis, Santa Catarina, Brasil. 2004.

PRADO JR., Caio. A Questão Agrária no Brasil. São Paulo: Ed. Brasiliense, 1979.

RAMOS, Marise. Escola Unitária. In: CALDART, Roseli Salete; PEREIRA, Isabel Brasil; ALENTEJANO, Paulo; FRIGOTTO, Gaudêncio (Orgs.). Dicionário da Educação do Campo. 2. ed. Rio de Janeiro, São Paulo: Escola Politécnica de Saúde Joaquim Venâncio, Expressão Popular, p. 341-347,2012.

ROUSSO, Henry. A memória não é mais o que era. In. Ferreira, M. M; Amado, J., "Usos e abusos da História Oral". 3ª Ed. FGV, Rio de Janeiro, pp. 93-102.

SAVIANI, Dermeval. História das Ideias Pedagógicas no Brasil. 4. ed. Campinas: Autores Associados, 2013.

SELONK, Marcus. José Takahashi. Jacarezinho: paradoxo de prosperidade e miséria. Rev. Mediações, Londrina, v. 4, n. 2, p.76-87, jul./dez. 1999.

TAVARES, Maria da Conceição. A questão agrária e as relações de poder no país. Folha de São Paulo. São Paulo, 1996.

THOMPSON, Edward Palmer. As Peculiaridades dos Ingleses e outros artigos. Campinas. Ed. UNICAMP, 2001. 